\title{
Experimental studies of the transporting capacity of the pipe textured relief trays
}

\author{
Vladimir Orlov", and Irina Dezhina \\ Moscow State University of Civil Engineering, Yaroslavskoe shosse, 26, Moscow, 129337, Russia
}

\begin{abstract}
The article presents an analysis of theoretical approaches to assessing the gravity pipeline efficiency in the transportation of water containing suspended solids (the sand). The attention is focused on application of the pipeline protective coatings used in their trenchless repair. Provision has been made of studying the problems of the removal of caked deposits on the pipe walls by creating a special pipeline textured inner surface, representing some kind of a relief, which favors the forced effect of flow turbulence in combination with the hydrophobic properties of the pipeline inner surface. The article presents the results of the research works on the creation of small-size hydraulic benches, which allow determination of the degree of the flow hydrophobicity and the transporting capacity along various textured surfaces (the pipeline protective coatings). The article describes the methods of work on the benches, types of obstacles and the nature of their arrangement along the length of the tray. Provision has been made of different options of the pipeline surface relief further improvement. The photo and film fixation, as well as the black-and-white shadow effects, have enabled presentation of the results of full-scale research experiments on the removal of various size suspended solids from the pipeline tray part. The micro-turbulence phenomena depending on the height of obstacles and their location have been described. The prospects and practical significance of the works aimed at improving the flow transport capacity have been assumed.
\end{abstract}

\section{Introduction}

The pipelines of water discharge systems, which are subject to trenchless repair by applying various types of internal protective coatings in the form of thin-walled sleeves (shells), are characterized by a number of parameters, which first of all include their strength and hydraulic characteristics $[1,2]$. When using new composite and polymer materials in the repair of pipelines in recent years, a special attention has been paid to the hydrophobic parameters, which can also be attributed to the hydraulic characteristics of pipes and their protective coatings [3].

To ensure an efficient transportation of waste waters containing a large amount of suspended solids through gravity pipelines, it is necessary to create a number of conditions that affect the flow rate, in particular, to ensure the appropriate pipe tray slopes and filling,

\footnotetext{
Corresponding author: orlov950@yandex.ru
} 
as well as a certain texture of their inner surface $[4,5]$. Thus, it can be stated, that the study of hydraulic characteristics for different types of protective coatings is currently relevant.

As is known, the hydraulic parameters should be determined experimentally using different types of benches [6, 7]. In 2017-2018, the employees of the Department «Water supply and Sewerage» of the Moscow state university of civil engineering conducted a comprehensive analysis of a large number of questions covering a wide range of issues related to the study of hydraulic (including hydrophobic) indicators of protective coatings, their transporting capacity, including the development of a software program of computeraided calculation of hydraulic parameters [8].

The researchers paid special attention to such issues as the condition of the inner surface of the pipes (especially those of small diameters of 100-200 mm), which, as possible, should have the minimum hydraulic friction values, that contributes to the efficient water flow both with the suspended particles [9]. In this aspect, provision shall be made of prediction of the critical deposition rate and, as a consequence, the influence of the average rate and filling, as well as the pressure gradient in the flow direction which enables a free removal of suspended solids to be carried out [10].

The composition of suspended substances, their concentration, particle size and the degree of the mixture homogeneity should also be assessed [11]. As indicated in [12], an ideal variant of the pipe inner surface seems to be such an option, that it should be possible to transport the suspended particles even at the rates below the critical ones (less than 0.7 $\mathrm{m} / \mathrm{s}$ ). However, if the flow rate for a long time remains below the critical (self-cleaning) value, the impurities are not retained in the suspended state and precipitate, forming dense deposits. At the same time, even the smooth inner surface of the pipes will not facilitate the movement of precipitated and caked mineral and organic contaminants, since the turbulent flow mode is transformed into a laminar one. The experiments procedure has been guided by the fact that some deposits, mainly in the upper layers with a relatively large filling in the pipeline, may be carried out by the flow in the hours of the maximum water consumption, and the caked ones will remain in the tray part of the pipe requiring a periodic cleaning of the pipeline by various methods. The automated calculations show that such a situation can lead to inefficient operation of the pipeline system: a decrease in its productivity or additional costs to overcome friction forces as a result of narrowing the live cross-section of pipelines $[13,14]$.

Herewith, the maintenance of the weighed substances in the most turbid condition would reduce the number of caked sediments. In this regard, the researchers put forward the idea of creating and studying a special surface structure having a special relief in the form of obstacles, which causes a forced flow turbulence effect combined with the hydrophobic properties of the pipeline inner surface [15].

\section{Materials and methods}

Two benches $[16,17]$ were designed and mounted to work out the hypothesis of the influence of hydrophobic, and subsequently structured surface of the tray part of the pipeline.

The test stand for determination of the hydrophobicity degree of the materials for the pipe manufacture and the pipeline repair has been made as an inclined tray with an adjustable slope and interchangeable work surfaces. After dispensing a so-called liquid «mini flow», the front and the coaxial cameras fixe its geometric parameters. For a schematic representation of the test bench see figure 1 . 


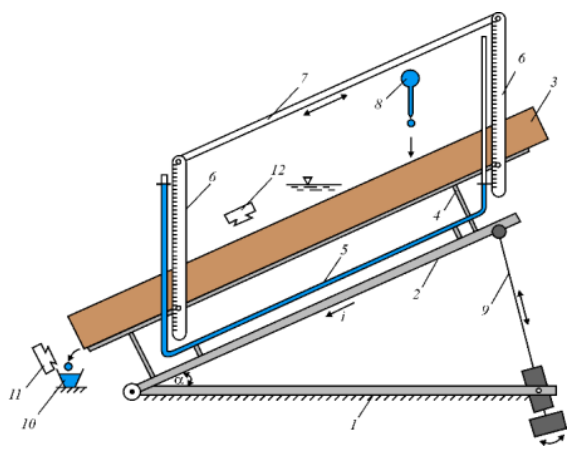

Fig. 1 Schematic drawing of the experimental equipment at the maximal slope of a $1 \mathrm{~m}$ long chute: 1 - support frame; 2 - rack; 3 - an open chute (tray); 4 - posts; 5 - the system of communicating vessels; 6 -measuring rules; 7 - the control bar; 8 - pipette with water; 9 - rod mechanical Jack; 10 a collection of drops; 11, 12 -respectively, the camera of frontal and coaxial front shooting of the flow

The test bench is equipped with a specially developed automated software program to accelerate and improve the accuracy of the calculations of the specified parameters. According to the developed technique, in addition to getting the relative hydrophobicity index for subsequent comparison of the hydraulic characteristics of different types of protective coatings, provision is made of the design values of the Chézy coefficients and the Manning relative roughness.

Figure 2 shows a sketch of the test bench for the study of the transporting capacity of the flow in an open tray. The experiments have been targeted to creation of an artificial effect of the micro-turbulence at the low flow rates of the liquid in the tray. The purpose of the experiments was to provide special conditions for the liquid flow with a forced agitation of suspended substances in it by creating various structured relief surfaces on the tray inner surface. Herewith, a prospective model of the particle motion was considered not as their spontaneous drawing in the bottom part of the pipe, but as a spasmodic movement in the flow (without caking) [18]. In this case, the amount of the deposed sediments remains minimal regardless of the rates and the fillings of the pipeline. This effect can be achieved by placing obstacles of different shapes in the tray part of the pipeline. Herewith, the practical interest in creating the micro-turbulence flow effect is due to the potential greater efficiency of the pipeline network operation, namely, a reduced number of necessary cleanings of a pipeline section and, as a consequence, a less number of potential emergency situations [19].

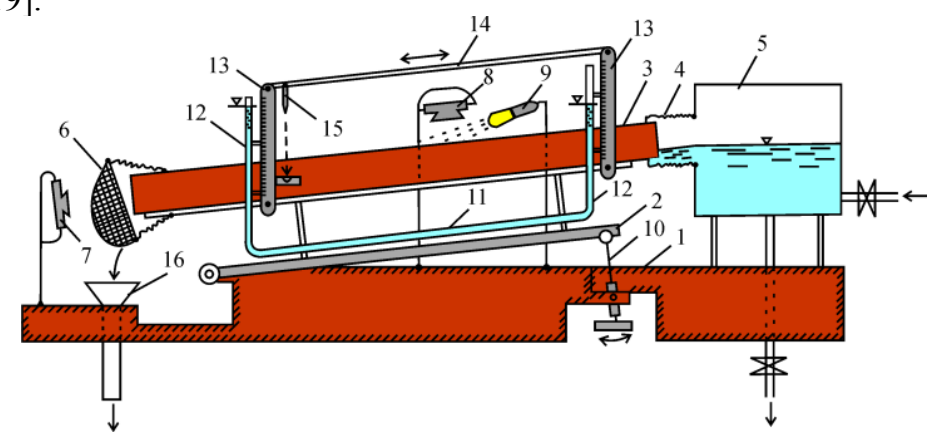

Fig. 2 Schematic depiction of the test stand for the study of turbulence and carrying capacity of the fluid flow by optical means: 1 - fixed frame; 2 - movable platform; 3 - open tray; 4 - rubber corrugated pipe; 5 - holding tank for liquid; 6 - removable mesh trap of foreign particulate inclusions; 7, 8 - cameras, respectively, of frontal and coaxial shooting; 9 - source of light radiation; 10 mechanical jack; 11 - waterway; 12 - flexible transparent connecting pipes; 13 - movable measuring lines; 14 - plate; 15 - laser plummet; 16 - receiving measuring tank 
The method of the bench work consists in the transportation of the liquid flow from a storage tank to an open tray (130 mm diameter) with different artificially made relief. There are various contaminants in the bottom of the tray, i.e. the sand of different grain size from 0.1 to $2.5 \mathrm{~mm}$. When the rate of the dispensed fluid flow has been increased from 0.2 to 0.8 $\mathrm{m} / \mathrm{s}$, the removal of the foreign inclusions has been observed. The efficiency of the solid particulate removal is controlled by a mesh catcher. The fluid flow rate has been determined by the volumetric method according to the fluid flow along a previously constructed calibrated curve. The adjustment of the working surface slope has been made by a mechanical Jack and a system of communicating vessels.

When a source of the light radiation is switched on, the film and photographic equipments, due to the black and white shadow effect, enable the capture of the following phenomena on the flow surface: formation of the micro-turbulence, transportation of turbid sediments along the tray and the geometrical parameters of the flow (length, width and area of the disturbance zones), as well as its character (the height of the layer, filling).

During the experimental studies on the testing bench, the micro-turbulence phenomena have been studied on different surface relief, and the pattern of the muddy agitation and movement of different fractions of the sand has been recorded in a wide range of flow rates (velocities). As the patterned surfaces provision has been made of several types of grouped obstacles, which have been symmetrically located in the bottom of the tray on both sides of its centerline.

\section{Results and discussion}

1. The works on the hydrophobicity study testing bench resulted in detailed frontal and coaxial photos, which show the behavior of a mini-flow flowing along various protective coatings of the tray. As such coatings used for trenchless repair techniques there were investigated polypropylene, polymer sleeve by foreign firms «Per Aarsleff» (Denmark) and «Wawin» (Holland), protective thin films of the company «3M» (USA), etc. In addition, the Smart Surface coating, developed by FUJIFILM HUNT (Belgium), which belongs to the category of hydrophobic ones, has been also subject to the hydrophobicity investigation.

The Figure 3 shows, as an example, the front view of a mini flow on one of the protective coatings applied to the open chute..

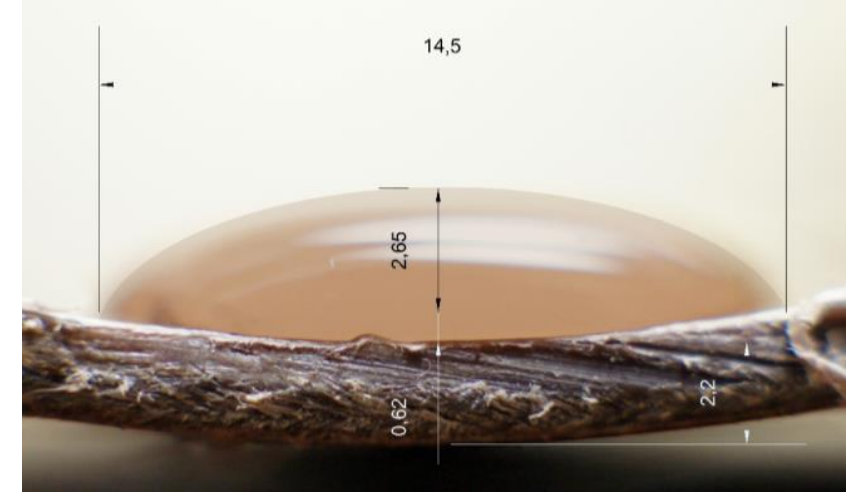

Fig. 3. Front view of a mini flow on the surface of the polypropylene tray

As a result of the experiments, a correlation between the relative hydrophobicity and roughness coefficients was found: the higher the hydrophobicity, the less the roughness of the material. The obtained design information can be considered as an auxiliary tool for a specialist (designer) to assess the hydraulic performance of the appropriate type of a protective coating. 
2. The investigation results aimed at evaluating the solid inclusion transportation efficiency apply to a unique type of obstacles, namely, the bars made of polymeric material of rectangular cross section with a length of about $20 \mathrm{~mm}$, a height of $2 \mathrm{~mm}$, which have been symmetrically installed at an angle of about $30^{\circ}$ to the axis of the tray. The position of the bars has been made as a so-called «straight tree», «reverse tree», and a «double row tree», which combined the previous two shapes. The sand of different size (1.5 and $2.5 \mathrm{~mm})$ and weight dosage has been used as a model of solid inclusions in water. A mesh catcher was used to control the removal of suspended solids.

The Tables 1 and 2 present the results of experimental studies with the type of the obstacle arrangement «straight» and «reverse» trees for the sand fractions of $1.5 \mathrm{~mm}$ and $2.5 \mathrm{~mm}$.

Table 1. The results of removal of sand impurities for sand size fractions of 1.5 and $2.5 \mathrm{~mm}$ at the «straight tree» obstacle location.

\begin{tabular}{|c|c|c|c|}
\hline $\begin{array}{c}\text { The picture of removal of the sand (1.5 } \\
\mathrm{mm})\end{array}$ & $\begin{array}{c}\text { Water } \\
\text { flow } \\
\text { rate, } \mathrm{m} / \mathrm{s}\end{array}$ & $\begin{array}{c}\text { The picture of removal of the } \\
\text { sand }(2.5 \mathrm{~mm})\end{array}$ & $\begin{array}{c}\text { Water } \\
\text { flow rate, } \\
\mathrm{m} / \mathrm{s}\end{array}$ \\
\hline & 0.38 & & 0.47 \\
\hline & 0.48 & & 0.62 \\
\hline
\end{tabular}

A visual analysis of the sand removal efficiency shows a greater removal efficiency of the sand of a smaller size with the same arrangement of obstacles and the same water flow rate. Herewith, when the flow rate is less than $0.3 \mathrm{~m} / \mathrm{s}$, the effect of agitation is practically absent. Upon reaching a speed of $0.4-0.5 \mathrm{~m} / \mathrm{s}$, the effect of micro-turbulence begins to appear (much more evidently for the sand of smaller size), but there occurs formation of accumulated sand particles along the water's edge from the lower side. When the flow rate reaches values of more than $0.6 \mathrm{~m} / \mathrm{s}$, the pattern of removal of sand of different sizes begins to differ significantly, i.e. the $2.5 \mathrm{~mm}$ sand is almost completely washed out along the tray axis without the flushing at the tray edges, namely with the sand accumulation on the water's edge. As regarding the $1.5 \mathrm{~mm}$ sand at the rate of $0.66 \mathrm{~m} / \mathrm{s}$, there is a complete removal throughout the tray.

The analysis of the sand removal efficiency results on the «reverse tree» shape showed some similar results. The accumulation of sand near the water's edge begins when the water rate achieves $0.5-0.6 \mathrm{~m} / \mathrm{s}$. The study of the substance removal dynamics allowed the forecast of the need in creating a second row of obstacles that ensure the sand washing out from the boundary zones under a water greater filling. 
Table 2. Results of removal of sand impurities for sand size fractions of 1.5 and $2.5 \mathrm{~mm}$ at the «reverse tree» obstacle location.

\begin{tabular}{|c|c|c|c|}
\hline $\begin{array}{c}\text { The picture of removal of the } \\
\text { sand }(1.5 \mathrm{~mm})\end{array}$ & $\begin{array}{c}\text { Water } \\
\text { flow } \\
\text { rate, } \mathrm{m} / \mathrm{s}\end{array}$ & $\begin{array}{c}\text { The picture of removal of the } \\
\text { sand }(2.5 \mathrm{~mm})\end{array}$ & $\begin{array}{c}\text { Water } \\
\text { flow rate, } \\
\mathrm{m} / \mathrm{s}\end{array}$ \\
\hline & 0.34 & & 0.31 \\
\hline & 0.39 & & \\
\hline & 0.45 & & \\
\hline
\end{tabular}

The Table 3 presents the results of experimental studies on the «double row tree», which is an obstacle with four symmetrically arranged rows.

At low fluid flow rates, such as $0.3 \mathrm{~m} / \mathrm{s}$, there is no effect of increasing the transporting capacity on any of the surfaces. Upon reaching a rate of $0.4 \mathrm{~m} / \mathrm{s}$ and more the sand of 2.5 $\mathrm{mm}$ size begins to accumulate in the form of lines along the water's edge; for sand of 1.5 $\mathrm{mm}$ size this effect appears only when the rate makes $0.5 \mathrm{~m} / \mathrm{s}$. The further increase in the rate of more than $0.6 \mathrm{~m} / \mathrm{s}$ and the presence of sand of $1.5 \mathrm{~mm}$ diameter there has been observed its active movement along the axis of the tray. When the diameter of the sand size is $2.5 \mathrm{~mm}$, the sand accumulation begins on the water's edges both below and above. The rate increase up to $0.7 \mathrm{~m} / \mathrm{s}$ for the sand of $2.5 \mathrm{~mm}$ diameter helped to reduce the number of sand accumulations on both water's edges and to enable its full removal at the rate of 0.83 $\mathrm{m} / \mathrm{s}$. Herewith, the $1.5 \mathrm{~mm}$ sand has been completely removed only when the flow rate has been increased (almost doubled - up to $1.63 \mathrm{~m} / \mathrm{s}$ ). The sand removal along the axis of the tray occurred after reaching a flow rate of $0.79 \mathrm{~m} / \mathrm{s}$. The latter means, that under a doublerow arrangement of obstacles, if all other conditions remain the same, the sand of a relatively fine fraction will be washed out by the flow from the tray less efficiently. The got results are intermediate ones and require further confirmation in conditions of wider ranges of water flow rates, tray fillings and sand size diameters. 
Table 3. Results of removal of sand impurities for sand size fractions of 1.5 and $2.5 \mathrm{~mm}$ at the «double row tree» obstacle location

\begin{tabular}{|c|c|c|c|}
\hline $\begin{array}{c}\text { The picture of removal of the } \\
\text { sand }(1.5 \mathrm{~mm})\end{array}$ & $\begin{array}{c}\text { Water flow } \\
\text { rate, } \mathrm{m} / \mathrm{s}\end{array}$ & $\begin{array}{c}\text { The picture of removal of the } \\
\text { sand }(2.5 \mathrm{~mm})\end{array}$ & $\begin{array}{c}\text { Water flow } \\
\text { rate, } \mathrm{m} / \mathrm{s}\end{array}$ \\
\hline & 0.32 & 0.34 \\
\hline
\end{tabular}

\section{Conclusions}

1. To solve the problem of studying the hydrophobic characteristics and the transporting capacity of the flow in open trays with an internal textured relief, provision has been made of creation of special small-size testing benches in combination with the methods of investigation tests of various types of protective coatings and pipelines.

2. The design of small-size benches for the study of the flow hydrophobicity and transporting capacity based on the use of optical means and black and white effect can compete with large-sized hydraulic installations in terms of reducing the cost of their construction, as well as the efficiency of full-scale test performance.

\section{References}

1. Wei G., Xu R., Huang B. Analysis of stability failure for pipeline during long distance piejacking. Chin. J. of Rock Mech. and Eng. 24 (8) 1427-1432 (2005)

2. Zakharov Y.S., Orlov V.A. Vosstanovleniye vodootvodyashih setey polimernimi rukavami. [Reconstruction of drainage networks polymer sleeves] (Moscow, Rusyns, 2007)

3. V. Orlov, MATEC Web of conf. 86, 04020 (2016) 
4. Grossmann S., Lohse D. Eur. Phys. J. E. 2017. 40, 16-19 (2017)

5. Arolla S.K., Desjardins O. Int. J. of Multiphase Flow, 7, 1-11 (2015)

6. Kuliczkowski A., Kuliczkowska E., Zwierzchowska A. Technologie beswykopowe w inzeynierii srodowiska. (Wydawnictwo Seidel-Przywecki Sp, 2010)

7. Otstavnov A. A., Hantai I. S., Orlov E. V., J. Plasticheskie massy, 1, 40-43 (2007)

8. Orlov V.A., Zotkin S.P., Dezhina I.S., Pelipenko A.A. The certificate of state registration of computer programs No. 2017612281 (2017)

9. Houghtalen R., Osman A., Akan A., Hwang N. Fundamentals of Hydraulic Engineering Systems, 5th edition. (Pearson, 2016)

10. Coleman S. Nikora V., J. Wat. Res. Research, 45 (4), 1-12 (2009)

11. Ebtehaj I., Bonakdari H., Water Sci Technol., 70(10), 695-701 (2014)

12. Bailey S.C.C., Vallikivi M., Hultmark M., Smits A. J., Fluid Mech. 749, 79-98 (2014)

13. Golubev V. O. J. Math. Designer, 1, 58-64 (2016)

14. Cazanescu S, Maracineanu F, Tadjer, J. Bul. sti. Univ. «Politehn.» Timisoara. Ser. Hidrotehn. 55 (1-2), 81-86 (2010)

15. Girginov A. D. Mag. of civil Eng, 5(23), 49-52 (2011)

16. Orlov V.A., Dezhina I.S., Orlov E.V., Averkeev I.A, Pat. (Russia) 157695 (2015)

17. Orlov V.A., Dezhina I.S., Pelipenko A.A., Orlov E.V. Pat. (Russia) 176330 (2018)

18. Bryanskaya Yu. V. Magazine of civil Eng, 6(41), 31-38 (2013)

19. Otstavnov A. A. J. Plasticheskie massy, 4, 2-4 (2004) 